\title{
The effect of different work-rest schedules on ergonomic risk in poultry slaughterhouse workers
}

\author{
Natália Fonseca Dias ${ }^{\mathrm{a}, *}$, Adriana Seára Tirloni ${ }^{\mathrm{a}}$, Diogo Cunha dos Reis ${ }^{\mathrm{a}, \mathrm{b}}$ and Antônio Renato \\ Pereira Moro ${ }^{\mathrm{a}, \mathrm{b}}$ \\ ${ }^{a}$ Technological Center, Federal University of Santa Catarina, SC, Brazil \\ ${ }^{\mathrm{b}}$ Biomechanics Laboratory, CDS, Federal University of Santa Catarina, SC, Brazil
}

Received 16 July 2019

Accepted 3 July 2020

\begin{abstract}
.
BACKGROUND: Rest breaks are an organizational measure to reduce the high risk of upper limb work-related musculoskeletal disorders (UL-WMSDs) to which slaughterhouse workers are subject.

OBJECTIVE: To analyze the effect of different work-rest schedules on ergonomic risk in poultry slaughterhouse workers. METHODS: A total of 36 repetitive tasks was selected in a Brazilian slaughterhouse. Using the Occupational Repetitive Action (OCRA) Checklist, the level of exposure of workers to risk factors of UL-WMSDs in two work-rest schedules was evaluated. In the real condition, 6 rest breaks of 10 minutes were performed, and in the simulated condition, 3 rest breaks of 20 minutes.

RESULTS: The right side of the body presented a higher score on the OCRA Checklist (72\% of the tasks) than the left side $(p=0.037)$ in the real condition. Additionally, the OCRA score $(18.3 \pm 2.5)$ was significantly lower $(p<0.001)$ than the simulated condition $(21.9 \pm 3.0)$. It was verified that the risk level in simulated condition remained the same in $13(36 \%)$ tasks, while in $23(64 \%)$ tasks there was an increase in the risk level.

CONCLUSIONS: Work-rest schedule of 6 breaks of 10 minutes was better than 3 breaks of 20 minutes to reduce the risk of UL-WMSDs in poultry slaughterhouse workers.
\end{abstract}

Keywords: Pause, risk assessments, musculoskeletal disorders

\section{Introduction}

The Brazilian production of chicken meat reached 13.245 million tons in 2019 , with the consumption of 42.84 kilograms per inhabitant [1]. In that sector, Brazil is the leader in chicken meat exports and third place in world production [1]. According to the Brazilian Animal Protein Association [2], approximately 350,000 workers are directly employed in poultry slaughterhouses. However, this economic

\footnotetext{
*Address for correspondence: Natália Fonseca Dias, Rua Poeta Drummond, 171/2 - Canta Galo - Rio do Sul, SC, CEP: 89163083, Brazil. Tel.: +55 47 999146416; E-mail: ergonomia.nd@ gmail.com.
}

sector is among the main generators of work-related musculoskeletal disorders (WMSDs) [3].

Slaughtering tasks and meat processing involve a high degree of repetitive upper limb movements [4-8], inadequate postures [9, 10], monotony [11], cold environments with handling of products with low temperatures [12], use of hand tools such as knives and scissors $[13,14]$ as well as the pressure induced by time and targets [11], factors that justify the amount of registered WMSDs.

Studies in poultry slaughterhouses used the OCRA (Occupational Repetitive Action) method to evaluate the risk of WMSD development in the upper limbs $[5,6,8,15]$. This method is preferably recommended 
by ISO $11228-3: 2007$ - Ergonomics - Manual handling - Handling of low loads at high frequency, as it provides a detailed analysis of the main risk factors (mechanical and organizational of WMSD), it is applicable to "multi-task job" and provides criteria based on extensive epidemiological data - for forecasting the occurrence of UL-WMSD (upper limbs) in exposed working populations [16].

In this sense, Regulatory Norm $\mathrm{N}^{\circ} 36$ (NR-36) was established in 2013, with the purpose of reducing occupational hazards to workers, in addition to establishing the minimum requirements for the evaluation, control and monitoring of risks in tasks carried out in the Brazilian industries of meat processing [10].

As reported by NR-36, the rest breaks in slaughtering and meat processing industries must be performed by workers who perform tasks directly in the production process, which require repetitive and/or static or dynamic muscular overload of the neck, shoulders, back and upper and lower limbs. Nevertheless, these breaks should be distributed during the workday with a minimum duration of 10 minutes and a maximum of 20 minutes [10].

Research has shown that rest breaks have recovery effects, reducing pain and fatigue [17], increasing productivity [18], improving performance [19] and reducing the risk of accidents [20]. In addition, several studies have investigated the ideal duration, frequency and type of breaks to reduce WMSDs [20-22] and found that the risk of an injury at work has significantly decreased for any length of rest breaks.

Conversely, there were no studies regarding the classification of ergonomic risk related to the performance of rest breaks in slaughterhouses. Thus, the objective of this study was to analyze the effect of different work-rest schedules on the ergonomic risk in poultry slaughterhouse workers.

\section{Materials and methods}

This cross-sectional observational study was approved by the Committee of Ethics in Research with Human Beings, Federal University of Santa Catarina - Brazil, under protocol 2098/2011, according to the Declaration of Helsinki.

\subsection{Work organization}

The study was conducted in a poultry slaughterhouse in the south of Brazil, with around 1,600
Table 1

Organizational characteristics of work in the slaughterhouse

\begin{tabular}{ll}
\hline Organizational characteristics of work & \\
\hline Workday (h, min) & $8 \mathrm{~h} 00 \mathrm{~min}$ \\
Repetitive work (min/workday) & $400 \mathrm{~min}$ \\
Rest breaks (n x min) & $6 \times 10 \mathrm{~min}$ \\
Meal (min) & $60 \mathrm{~min}$ \\
Uniform change (min/workday) & $20 \mathrm{~min}$ \\
\hline
\end{tabular}

workers who slaughtered 180,000 chickens daily. The working time and other organizational characteristics of the company are shown in Table 1 .

\subsection{Participants}

A total of 36 repetitive tasks was selected in $9 \mathrm{sec}$ tors of the production process, from the arrival of the chicken in the industry to the meat cutting sector. The task selection was intentional, as it included activities that involved many workers, as well as those that demonstrated an ergonomic risk.

Those workers who performed the tasks previously defined were randomly selected, invited to participate in the study, provided the consent, and videotaped. For each task, at least 2 workers who performed the job according to standardization established by the company were filmed.

\subsection{OCRA checklist method}

The OCRA Checklist method assesses the workers exposure level to risk factors for UL-WMSD. For this, the variables: duration of repetitive tasks, lack of recovery periods, frequency of technical actions, force demand, inadequate postures, stereotypy and other additional risk factors were evaluated separately. The exposure risk was identified by the equation presented in Fig. 1 [15].

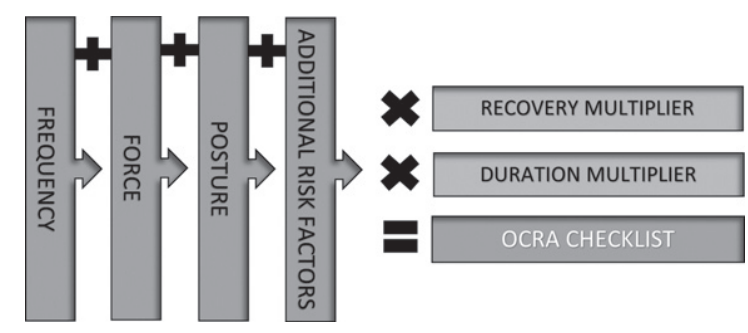

Fig. 1. Risk calculation of UL-WMSD development by the OCRA Checklist method. 


\subsubsection{Recovery multiplier}

Information on the quantity, duration and distribution of rest breaks during the workday were collected to designate the recovery multiplier. In the analyzed slaughterhouse, 6 rest breaks of 10 minutes were distributed each working hour, consequently, received the score of " 1 " for the recovery multiplier.

\subsubsection{Duration multiplier}

To determine the duration multiplier factor, the work organization was analyzed in order to identify the net time of the repetitive task performed by workers. Based on the total time of the workday, it subtracts the official and unofficial rest breaks, the time of nonrepetitive tasks and meal intervals (counted within the workday) resulting in the net repetitive task time, in minutes [15]. In the slaughterhouse studied, the net repetitive task time was 400 minutes (multiplier $=1$ ).

\subsubsection{Frequency factor}

Aiming to identify the number of technical actions carried out by the workers, an experienced researcher used a camcorder Sony HDR-XR160 to film the workers with the lateral and frontal view. It was done for at least two minutes with each worker, capturing on average 10 cycles. According to Colombini and Occhipinti [15], filming a few cycles (3 or 4) for each repetitive task is sufficient, and if the task allows variations of execution, it is advisable to film 2 to 3 workers.

Conforming to Colombini and Occhipinti [15], technical actions are identified by the set of movements of one or more articular segments, of the upper limbs, that allow the execution of each operation (i.e. pick up, position, push). This factor should be expressed in "technical actions per minute", and the higher the number of shares, the higher the score [15]. The counting of technical actions was performed individually among the upper limbs during the execution of each task, because different risk exposure levels have distinct probabilities of becoming ill.

\subsubsection{Force factor}

During the force factor evaluation, it is first necessary to identify the technical actions of the cycle that involve force, and then question the workers about the strength level perception for each of these technical actions of the task cycle using the Borg scale (0-10). Subsequently, needs to verify the duration of each action (\%), in which this force is applied during the cycle and, finally, to calculate the average strength score in relation to force technical actions of the cycle [15].

\subsubsection{Posture factor}

The posture factor score is obtained by the individual evaluation of the shoulders, elbows, wrists, hands and finger joints [15]. This factor was analyzed through the filming of the workers during the execution of their tasks, allowing the identification of inadequate range of motion. The score of this factor is generated conforming to the length of time in inappropriate postures $(1 / 3,2 / 3,3 / 3$ of the total cycle time) and only the highest value among the analyzed body segments is considered in the sum of the final score, together with the stereotypy [15].

The presence of dynamic or static technical actions that are repeated for more than $50 \%$ of the time is characteristic of the stereotype factor, which is added to the final value of the posture factor. In cycles with time $\leq 15$ seconds, with technical actions repeated for more than half the time, the score " 1.5 " is assigned and in situations with cycle time $<8$ seconds, with repeated technical actions almost all the time, the score " 3 " is added [15].

Table 2

Risk assessment of upper-limb repetitive movements according to the OCRA Checklist
Risk
OCRA Checklist Score
Incidence of UL-WMSDs (\%)

\begin{tabular}{cccc}
\hline Green & Acceptable & $<7.5$ & $<5.3$ \\
\hline Yellow & Very Low & $7.6-11$ & $5.3-8.4$ \\
\hline Light Red & Low & $11.1-14$ & $8.4-10.8$ \\
\hline Dark Red & Moderate & $14.1-22.5$ & $10.8-21.5$ \\
\hline Purple & High & $>22.5$ & $>21.5$ \\
\hline
\end{tabular}

Source: Colombini and Occhipinti [15]. 
Real Condition

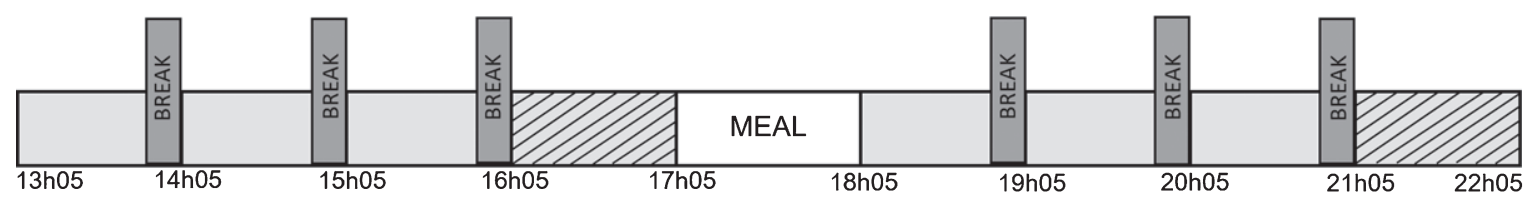

Simulated Condition

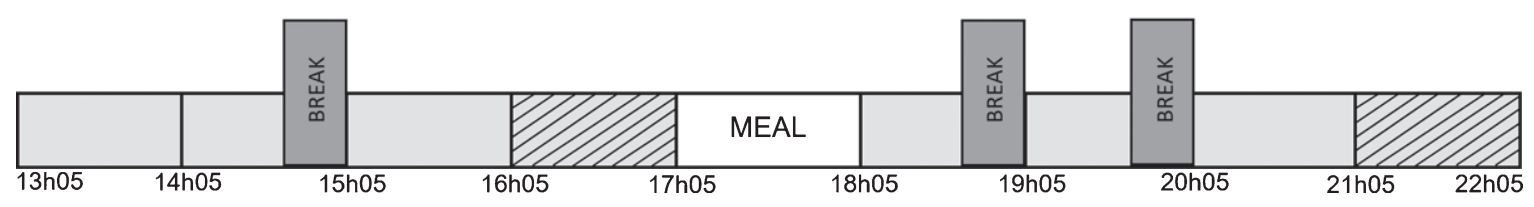

Fig. 2. Distribution of the rest breaks in a workday of 8 hours.

\subsubsection{Additional risk factors}

Finally, the complementary factors are various elements of physical-mechanical and/or organizational risks, in which the worker remains exposed during the workday [15]. For example, in the analyzed slaughterhouse, the most common complementary factor was the working pace completely determined by the machine.

The OCRA Checklist method classifies risk into five categories and relates it to the incidence of WMSD in upper limbs (Table 2).

The risk assessment was performed for both upper limbs, however, to determine the final risk classification, only the highest risk side was considered.

\subsection{Work-rest schedules}

Conforming to NR-36, the rest breaks in the slaughter and meat processing industries should be distributed in periods of at least 10 minutes and a maximum of 20 minutes. To detect the effect of different work-rest schedules in ergonomic risks, the present study analyzed two conditions (real and simulated), using the OCRA Checklist method (Fig. 2).

Real Condition - 6 rest breaks of 10 minutes in a workday of 8 hours.

Simulated Condition - 3 rest breaks of 20 minutes in a workday of 8 hours.

The method considers that the hour before the meal break and before the end of the workday are automatically recovered hours [15]. The recovery multiplier increases according to the number of hours without recovery. In the real condition, since there were no hours without recovery, the factor assigned was " 1 ". In the simulated condition, 3 hours were identified without recovery the score "1.2" was attributed.

\subsection{Statistical analysis}

Statistical analyses were performed using IBM SPSS Statistics, version 21.0 (IBM Corp., Armonk, NY, USA), and data was presented through means, standard deviations, frequencies, and percentages. The Shapiro-Wilk test was used to verify the normality of the OCRA Checklist scores in relation to bilateral body assessments and work-rest schedules (real and simulated conditions). The Wilcoxon paired test was applied to compare the results of the OCRA Checklist among the hemibodies and organizational conditions. For all tests, a statistical significance level of $p \leq 0.05$ was adopted.

\section{Results}

Among the 36 tasks analyzed, the right side of the body presented a higher score on the OCRA Checklist (72\% of the tasks). In the real work-rest schedule, the score of the right side was $17.7 \pm 3.1$ and the left was $16.3 \pm 3.5$, being significantly higher on the right side $(p=0.037)$. Regarding the frequency factor, the workers performed $73.7 \pm 24.3$ technical actions per minute.

The result of the OCRA Checklist in the real condition was $18.3 \pm 2.5$, while in the simulated condition, it was $21.9 \pm 3.0$ (both at moderate risk) (Table 3). In the real condition, the score was significantly lower $(p<0.001)$, in which the workers performed 6 rest breaks of 10 minutes. It was observed that the risk increased by $20 \%$ when the organization of the rest breaks changed from real to simulated, because the duration multiplier was 1 in the real condition and 1.2 in the simulated. 
Table 3

Description of the risk assessment of the tasks using the OCRA Checklist method in different work-rest schedules

\begin{tabular}{|c|c|c|c|c|c|c|c|c|c|c|c|c|c|c|c|c|c|}
\hline Sectors & Tasks & $\begin{array}{l}\text { Duration } \\
\text { M. }\end{array}$ & $\begin{array}{c}\text { Technical } \\
\text { actions/ } \\
\text { min }\end{array}$ & $\begin{array}{c}\text { Recovery } \\
\text { M. } \\
\text { (Real) } \\
\end{array}$ & $\begin{array}{c}\text { Recovery } \\
\text { M. } \\
\text { (Simulated) } \\
\end{array}$ & Frequency & Force & $\begin{array}{l}\text { Body } \\
\text { Side }\end{array}$ & Shoulder & Elbow & Wrist & $\begin{array}{l}\text { Hand - } \\
\text { fingers }\end{array}$ & $\begin{array}{l}\text { Stere- } \\
\text { otypy }\end{array}$ & $\begin{array}{l}\text { Posture - } \\
\text { Total }\end{array}$ & $\begin{array}{l}\text { Additional } \\
\text { factors }\end{array}$ & $\begin{array}{l}\text { OCRA } \\
\text { (Real) }\end{array}$ & $\begin{array}{c}\text { OCRA } \\
\text { (Simulated) }\end{array}$ \\
\hline \multirow[t]{6}{*}{ Wing } & Removing chicken wings & 0.95 & 87.0 & 1 & 1.2 & 10 & 2 & $\mathrm{~L}$ & 1 & 2 & 2 & 4 & 3 & 7 & 2 & 20.0 & 23.9 \\
\hline & Packing chicken wings & 0.95 & 50.8 & 1 & 1.2 & 6 & 2 & $\mathrm{R}$ & 4 & 2 & 2 & 4 & 3 & 7 & 2 & 16.2 & 19.4 \\
\hline & Interfolding chicken wings & 0.95 & 104.6 & 1 & 1.2 & 10 & 0 & $\mathrm{R}$ & 1 & 0 & 2 & 6 & 3 & 9 & 2 & 20.0 & 23.9 \\
\hline & Weighting chicken wings & 0.95 & 71.9 & 1 & 1.2 & 10 & 2 & $\mathrm{~L}$ & 1 & 2 & 2 & 4 & 3 & 7 & 2 & 20.0 & 23.9 \\
\hline & Chicken wing splitting & 0.95 & 88.2 & 1 & 1.2 & 10 & 0 & $\mathrm{R}$ & 4 & 2 & 2 & 4 & 3 & 7 & 2 & 18.1 & 21.7 \\
\hline & Sorting chicken wings & 0.95 & 59.0 & 1 & 1.2 & 8 & 0 & $\mathrm{R}$ & 1 & 2 & 2 & 4 & 3 & 7 & 2 & 16.2 & 19.4 \\
\hline Stork & Re-hanging Stork & 0.95 & 64.0 & 1 & 1.2 & 9 & 2 & $\mathrm{R}$ & 1 & 2 & 2 & 4 & 3 & 7 & 2 & 19.0 & 22.8 \\
\hline Whole & $\begin{array}{l}\text { Re-hanging } \\
\text { whole chicken }\end{array}$ & 0.95 & 64.2 & 1 & 1.2 & 9 & 2 & $\mathrm{R}$ & 1 & 2 & 2 & 4 & 3 & 7 & 2 & 19.0 & 22.8 \\
\hline \multirow[t]{3}{*}{ Kakugiri } & $\begin{array}{l}\text { Fueling kakugiri } \\
\text { conveyor belt }\end{array}$ & 0.95 & 115.4 & 1 & 1.2 & 10 & 0 & $\mathrm{R}$ & 1 & 2 & 2 & 6 & 3 & 9 & 2 & 20.0 & 23.9 \\
\hline & Sorting kakugiri & 0.95 & 70.2 & 1 & 1.2 & 10 & 2 & $\mathrm{R}$ & 1 & 4 & 2 & 4 & 3 & 7 & 2 & 20.0 & 23.9 \\
\hline & $\begin{array}{l}\text { Distribute kakugiri } \\
\text { on conveyor }\end{array}$ & 0.95 & 97.5 & 1 & 1.2 & 10 & 0 & $\mathrm{R}$ & 1 & 2 & 2 & 6 & 3 & 9 & 2 & 20.0 & 23.9 \\
\hline \multirow[t]{9}{*}{ Viscera } & Packing viscera & 0.95 & 42.1 & 1 & 1.2 & 4 & 2 & $\mathrm{~L}$ & 1 & 0 & 2 & 4 & 3 & 7 & 2 & 14.3 & 17.1 \\
\hline & Weighting viscera & 0.95 & 50.6 & 1 & 1.2 & 6 & 0 & $\mathrm{~L}$ & 1 & 0 & 2 & 4 & 3 & 7 & 2 & 14.3 & 17.1 \\
\hline & Weighting chicken feet & 0.95 & 65.0 & 1 & 1.2 & 9 & 2 & $\mathrm{R}$ & 4 & 2 & 2 & 4 & 3 & 7 & 2 & 19.0 & 22.8 \\
\hline & Sorting chicken hearth & 0.95 & 82.0 & 1 & 1.2 & 10 & 2 & $\mathrm{R}$ & 2 & 2 & 2 & 4 & 3 & 7 & 2 & 20.0 & 23.9 \\
\hline & Cleaning chicken gizzard & 0.95 & 81.5 & 1 & 1.2 & 10 & 2 & $\mathrm{R}$ & 1 & 1 & 2 & 4 & 3 & 7 & 2 & 20.0 & 23.9 \\
\hline & Chicken liver prepping & 0.95 & 103.0 & 1 & 1.2 & 10 & 2 & $\mathrm{R}$ & 2 & 2 & 2 & 4 & 3 & 7 & 2 & 20.0 & 23.9 \\
\hline & Sealing viscera packing & 0.95 & 42.1 & 1 & 1.2 & 4 & 2 & $\mathrm{~L}$ & 1 & 0 & 2 & 2 & 3 & 5 & 2 & 12.4 & 14.8 \\
\hline & $\begin{array}{l}\text { Sealing chicken } \\
\text { feet packing }\end{array}$ & 0.95 & 52.6 & 1 & 1.2 & 7 & 2 & $\mathrm{R}$ & 2 & 2 & 2 & 4 & 3 & 7 & 2 & 17.1 & 20.5 \\
\hline & Sorting chicken gizzard & 0.95 & 62.0 & 1 & 1.2 & 8 & 2 & $\mathrm{~L}$ & 2 & 2 & 2 & 4 & 3 & 7 & 2 & 18.1 & 21.7 \\
\hline \multirow[t]{5}{*}{ Breast } & Sorting chicken breast & 0.95 & 70.0 & 1 & 1.2 & 10 & 2 & $\mathrm{R}$ & 2 & 2 & 2 & 4 & 3 & 7 & 2 & 20.0 & 23.9 \\
\hline & Breast X-ray inspection & 0.95 & 141.5 & 1 & 1.2 & 10 & 0 & $\mathrm{R}$ & 1 & 0 & 4 & 6 & 3 & 9 & 2 & 20.0 & 23.9 \\
\hline & Cleaning chicken breast & 0.95 & 82.7 & 1 & 1.2 & 10 & 2 & $\mathrm{~L}$ & 1 & 2 & 2 & 4 & 3 & 7 & 2 & 20.0 & 23.9 \\
\hline & Chicken skin prepping & 0.95 & 75.5 & 1 & 1.2 & 10 & 0 & $\mathrm{~L}$ & 4 & 2 & 2 & 4 & 3 & 7 & 2 & 18.1 & 21.7 \\
\hline & Sealing breast packaging & 0.95 & 69.0 & 1 & 1.2 & 10 & 4 & $\mathrm{~L}$ & 6 & 2 & 2 & 5 & 3 & 9 & 2 & 23.8 & 28.5 \\
\hline \multirow[t]{4}{*}{ Legs } & Sorting chicken legs & 0.95 & 108.0 & 1 & 1.2 & 10 & 2 & $\mathrm{R}$ & 2 & 2 & 2 & 4 & 3 & 7 & 2 & 20.0 & 23.9 \\
\hline & Packing chicken legs & 0.95 & 77.7 & 1 & 1.2 & 10 & 2 & $\mathrm{R}$ & 2 & 2 & 2 & 4 & 3 & 7 & 2 & 20.0 & 23.9 \\
\hline & Cleaning chicken legs & 0.95 & 92.5 & 1 & 1.2 & 10 & 2 & $\mathrm{R}$ & 1 & 2 & 2 & 3 & 3 & 6 & 2 & 19.0 & 22.8 \\
\hline & Re-hanging chicken legs & 0.95 & 60.0 & 1 & 1.2 & 8 & 2 & $\mathrm{R}$ & 2 & 4 & 4 & 4 & 3 & 7 & 2 & 18.1 & 21.7 \\
\hline \multirow{4}{*}{$\begin{array}{l}\text { Reception } \\
\text { of chickens }\end{array}$} & Unloading cages & 0.95 & 48.6 & 1 & 1.2 & 6 & 4 & $\mathrm{R}$ & 4 & 4 & 2 & 4 & 3 & 7 & 1 & 17.1 & 20.5 \\
\hline & $\begin{array}{l}\text { Stacking cages - } \\
\text { high height }\end{array}$ & 0.95 & 32.7 & 1 & 1.2 & 2 & 4 & $\mathrm{R}$ & 4 & 2 & 2 & 2 & 3 & 7 & 1 & 13.3 & 16.0 \\
\hline & $\begin{array}{l}\text { Stacking cages - } \\
\text { low height }\end{array}$ & 0.95 & 83.4 & 1 & 1.2 & 10 & 4 & $\mathrm{R}$ & 4 & 4 & 2 & 4 & 3 & 7 & 1 & 20.9 & 25.1 \\
\hline & Hanging chickens & 0.95 & 42.0 & 1 & 1.2 & 4 & 4 & $\mathrm{R}$ & 4 & 4 & 2 & 4 & 3 & 7 & 2 & 16.2 & 19.4 \\
\hline \multirow[t]{5}{*}{ Sassami } & $\begin{array}{l}\text { Distribute sassami on } \\
\text { conveyor belt scale }\end{array}$ & 0.95 & 94.0 & 1 & 1.2 & 10 & 0 & $\mathrm{R}$ & 1 & 0 & 2 & 4 & 3 & 7 & 2 & 18.1 & 21.7 \\
\hline & Sorting sassami & 0.95 & 86.0 & 1 & 1.2 & 10 & 2 & $\mathrm{~L}$ & 2 & 2 & 2 & 4 & 3 & 7 & 2 & 20.0 & 23.9 \\
\hline & Cleaning sassami & 0.95 & 36.0 & 1 & 1.2 & 2 & 2 & $\mathrm{R}$ & 1 & 2 & 2 & 4 & 3 & 7 & 2 & 12.4 & 14.8 \\
\hline & Average & 0.95 & 73.7 & 1 & 1.2 & 8.4 & 1.8 & & 2.1 & 1.9 & 2.1 & 4.1 & 3 & 7.2 & 1.9 & 18.3 & 21.9 \\
\hline & Standard-deviation & 0 & 24.3 & 0 & 0 & 2.5 & 1.2 & & 1.4 & 1.1 & 0.5 & 0.9 & 0 & 0.8 & 0.3 & 2.5 & 3.0 \\
\hline
\end{tabular}


Real Condition

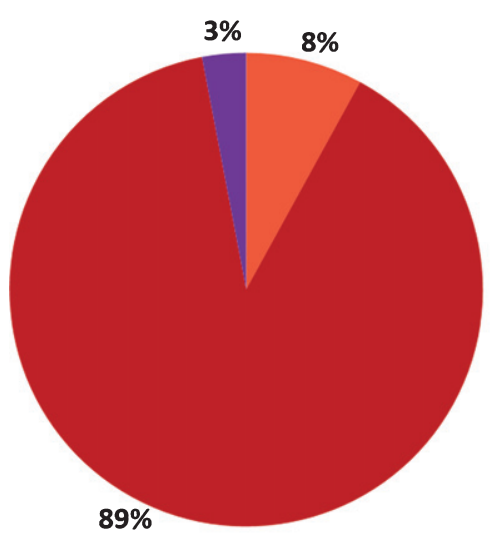

Simulated Condition

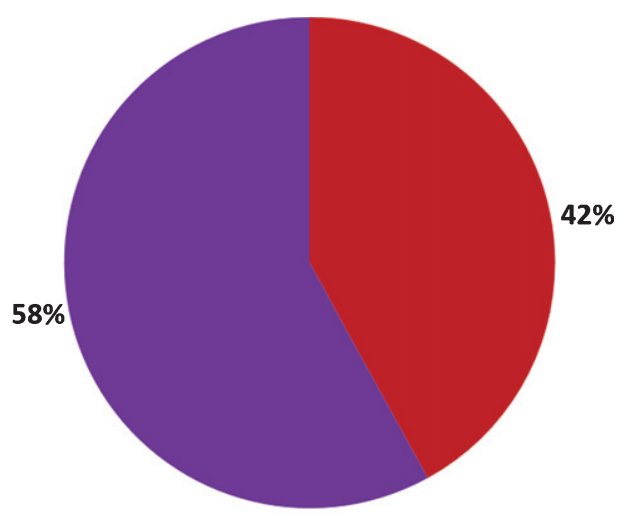

- Low Moderate High

Fig. 3. Risk classification of tasks in the real and simulated conditions of rest breaks.

In relation to risk classification, it was verified that most of the tasks presented moderate risk (89\%) in the real condition and high risk (58\%) in the simulated condition (Fig. 3).

When comparing the risk ratings of the real condition with the simulated condition, it was confirmed that the risk level remained in $13(36 \%)$ tasks, whereas in $23(64 \%)$ tasks, there was an increased risk in the simulated condition.

\section{Discussion}

The right side of the body presented a significantly higher score than the left side on the OCRA Checklist, corroborating with the studies of Reis et al. [5, 6, 8]. Tirloni et al. [23] found that most of the workers in a chicken slaughterhouse were right-handed (97.1\%) and had more discomfort in the right side of the body $(93.7 \%)$ than in the left $(84.2 \%)(p<0.001)$.

Studies in poultry slaughterhouses cited that most of the tasks analyzed were classified with moderate risk of developing WMSD, 81\% [5], 77\% [8] and $63 \%$ [6], similar to the present study in both conditions. On the other hand, one study in a poultry slaughterhouse detected that $56.5 \%$ of the tasks presented high risk [24]. Reis et al. [6] and Colombini and Ochipinti [15] suggest, as an organizational measure of decreased WMSD, that rest breaks are well distributed throughout the workday (every hour). The findings of the present study reinforce this recommendation, since in the real condition (breaks at each hour of work) the risk of WMSD was 20\% lower than in the simulated condition.

With a workers' perception approach $(n=45)$ of a poultry slaughterhouse, Camargo [25] found that $55 \%$ of workers were very satisfied with rest breaks of 20 minutes each, $38 \%$ were satisfied and only $7 \%$ were dissatisfied. The justification given by the workers who were dissatisfied was the inconvenience of removing and putting on the personal protective equipment (PPE) at each break, in addition to disapproving the short break (10 minutes), because they could not take advantage of the rest offered by the slaughterhouse.

As stated by Tirloni et al. [26], well-distributed rest breaks should be adopted throughout the workday in slaughterhouses for WMSD prevention. According to the US Department of Labor [9], an administrative (organizational) solution that can be used to reduce the duration and frequency of exposure to risk factors in poultry slaughterhouses is to allow pauses to rest the fatigued muscles. Prior to NR-36 implantation, the performance of rest breaks in Brazilian slaughterhouses was determined by NR-17, which only establishes the inclusion of rest breaks in tasks that require static or dynamic muscular overload of the neck, shoulders, back and upper and lower limbs [27], without specifying duration and/or frequency of this.

In addition to the distribution of breaks during the working day, the authors of the OCRA method reported that in repetitive tasks, breaks should be distributed in a ratio of at least 5:1 [15], i.e. for every 50 
minutes of work, there should be a 10-minute break for proper physiological recovery. The authors mentioned that besides the distribution, the duration of the breaks should be considered, and should last at least $8-10$ consecutive minutes. Nonetheless, NR36 allows breaks lasting 10 to 20 minutes, which can exceed one hour of continuous work, resulting in total rest break durations of 20, 45 and 60 minutes, according to the length of the workday [10].

As opposed to these recommendations on the minimum duration of a rest break, a control case study with farmers $(n=66)$ found that the experimental group (4 rest breaks of 5 minutes each during the workday) presented a significant decrease in musculoskeletal symptoms $(p=0.01)$. Conversely, there was no decrease in fatigue $(p=0.19)$ and an increase in productivity ( $p=0.66$ ) when compared to the group that performed a 10-minute rest for every 4 hours working and a 30-minute meal (Law of California, USA) [18].

A study with 400 embroiderers aimed to determine the risk factors that forecast musculoskeletal discomfort and compare the effect of two rest break timelines to reduce these symptoms. The first timeline at 5minute intervals for every 25 minutes of work and the second at 10-minute intervals for every 50 minutes of work. The results showed that the first schedule (more frequent and short rest breaks) had a significant result in the reduction of discomfort in the lower back, neck/shoulder and wrist/forearm [28].

In the real condition of this research, the breaks were passive. Conforming to NR-36, participation in any type of physical activity (active pause), when offered by the slaughterhouse, can be achieved only in one of the intervals intended for breaks, and worker participation is not mandatory [10]. No studies were found on the effects of active and passive breaks on slaughterhouse workers. Nevertheless, one study with eighteen healthy women performing a simulated task (industrial assembly work) in four different conditions: 1) slow or 2) fast work pace with 3) passive or 4) active pauses every two minutes revealed that the pause types had a limited effect, even though the active pauses caused increased RMS of the clavicular trapezius [29].

Notwithstanding, Dababneh et al. [30] researched the impact of two short break schemes on worker productivity in a meat processing industry: 3-minute breaks for every 27 minutes of work and 9-minute breaks for every 51 minutes of work. The results showed that none of the two experimental schemes had a negative effect on productivity. However, the 9-minute intervals improved the discomfort classifications for the lower extremities, in addition to being the preferred break scheme of workers.

In order to reduce or prevent hazardous exposures, the employers must provide breaks to limit continuous work to less than 2 hours [31]. Rest breaks are important where high-paced, repetitive work is performed and productivity falls quite quickly after the start of the shift, and scheduled breaks should be timed so that workers get a rest before their arms or shoulders become fatigued [32].

Tirloni et al. [23] analyzed the bodily discomfort in 312 poultry slaughterhouse workers and their associations with occupational risk factors. The workday at this slaughterhouse was 8 hours and 48 minutes, workers took a 45-minute break for meal, 16 minutes for physiological needs ( $2 \times 8$ minutes), 8 minutes of physical exercise at work and 25 minutes for snacks. The results showed that $71.2 \%$ of the workers felt discomfort in some region of the body, and of these, $64 \%$ perceived a reduction of discomfort due to rest breaks. Another study, carried out with 72 workers from a pig slaughterhouse, found that $93.3 \%$ of workers also reported reduction of discomfort due to rest breaks [12]. The body discomfort in slaughterhouse workers is high [12, 23, 33]. A study with 925 workers of three poultry slaughterhouses found that 661 workers felt body discomfort (71.5\%), and of these, $58.2 \%$ took medication to mitigate the reported symptoms [33].

Folkard et al. [34] investigated the incidence of industrial injuries in an engineering plant, in which 15-, 45- and 10-minute breaks were performed in this order after every two hours of work. The results indicated that the risk increased substantially between rest breaks, and the risk doubled in the last 30 minutes preceding the next rest break. Thus, the authors concluded that frequent breaks distributed every hour reduce workers' exposure to the risks of the task.

Contrary to the OCRA Checklist method, NR-36 mentions that the distribution of rest breaks should not occur in the first hour of work, contiguous with the meal interval and at the end of the last hour of the day [10]. It is noteworthy that the non-pause in the first hour of work, in the analysis of the OCRA method, changes the recovery multiplier factor of repetitive task from 1 to 1.05; which represents an increase of $5 \%$ in the final score value, consequently, an increase in risk.

Many studies confirm the need to take several breaks during the workday to reduce workers' exposure to risks $[10,15,21,22,31,34]$. In agreement 
with Colombini and Occhipinti [15], the longer the time of exposure to repetitive activities, the higher the duration multiplier score and, consequently, the higher the incidence of UL-WMSD.

\section{Limitations and future lines}

The present study reflects a selection bias, since the tasks were chosen intentionally. However, this interference in the study results was minimized because the proportion of risk level change (20\%) between the different rotation schemes was maintained, independent of the activities to be analyzed. It is suggested to carry out studies with larger samples and analyze the effects of different rotation schemes on variables such as body discomfort and level of illness of workers, making possible the use of more robust statistical tests and the generalization of the results.

\section{Conclusions}

It was concluded that the right side of the body presented a significantly higher score than the left side on the OCRA Checklist. The work-rest schedule adopted in the analyzed slaughterhouse (real condition -6 breaks of 10 minutes distributed each working hour) resulted in a significantly lower risk than the simulated condition, although the real condition is not recommended by NR-36. Considering the results of the OCRA method, it is proposed to carry out frequent and short breaks to reduce the risk of developing UL-WMSDs in slaughterhouse workers. Nevertheless, it is suggested to perform more robust studies on the satisfaction of slaughterhouse workers regarding the duration and frequency of breaks, as well as the relationship of this with bodily discomfort.

\section{Conflict of interest}

None to report.

\section{References}

[1] Associação Brasileira de Proteína Animal [homepage on the Internet]. Relatório Anual 2020. São Paulo: ABPA; 2020 [cited 2020, May 16]. Available from: http://abpabr.org/wp-content/uploads/2020/05/abpa_relatorio_anual_ 2020_portugues_web.pdf
[2] Associação Brasileira de Proteína Animal [homepage on the Internet]. Resumo do setor de aves: O Brasil Avícola. ABPA; 2018 [cited 2018, November 09]. Available from: http://abpa-br.com.br/setores/avicultura/resumo

[3] Anuário Estatístico de Acidentes do Trabalho: AEAT 2017. Ministério da Fazenda, Brasília; 2017.

[4] Sundstrup E, Jakobsen MD, Jay K, Brandt M, Andersen LL. High intensity physical exercise and pain in the neck and upper limb among slaughterhouse workers: crosssectional study. BioMed Research International. 2014;2014: 218546.

[5] Reis DC, Ramos E, Reis PF, Hembecker PK, Gontijo LA, Moro ARP. Assessment of risk factors of upper-limb musculoskeletal disorders in poultry slaughterhouse. Procedia Manufacturing. 2015;3:4309-14.

[6] Reis DC, Tirloni AS, Ramos E, Moro ARP. Assessment of Risk Factors of Upper-limb Musculoskeletal Disorders in a Chicken Slaughterhouse. Japanese Journal of Ergonomics. 2017;53:S458-S461.

[7] Reis DC, Tirloni AS, Ramos E, Dias NF, Moro ARP. Risk Assessment of Repetitive Movements of the Upper Limbs in a Chicken Slaughterhouse. In: Congress of the International Ergonomics Association. Springer: Cham; 2018. pp. 323-329.

[8] Reis DC, Moro ARP, Ramos E, Reis P. Upper limbs exposure to biomechanical overload: Occupational risk assessment in a poultry slaughterhouse. In: Goonetilleke R.; Karwowski W, editors. Advances in Physical Ergonomics and Human Factors. Cham: Springer; 2016, v.489, pp. 275-282.

[9] Occupational Safety and Health Administration (OSHA) [homepage on the Internet]. Prevention of musculoskeletal injuries in poultry processing. U.S. Department of Labor, 2013; [cited 2018 may 18]. Available from: https:// www.osha.gov/publications/osha3213.pdf.

[10] Brasil. Norma Regulamentadora No 36 - Segurança e saúde no trabalho em empresas de abate e processamento de carnes e derivados, Portaria MTE No 555, 18 de abril de 2013. Brasília: Ministério do Trabalho, 2013.

[11] Ministério do Trabalho. Manual de Auxílio na Interpretação e Aplicação da Norma Regulamentadora n ${ }^{\circ} 36$ : Segurança e Saúde no Trabalho em Empresas de Abate e Processamento de Carnes e Derivados. Brasília: Secretaria de Inspeção do Trabalho, 2017, pp. 254.

[12] Tirloni AS, Reis DC, Ramos E, Moro ARP. Evaluation of Bodily Discomfort of Employees in a Slaughterhouse. In: Goonetilleke RS, Waldemar K, editors. Advances in Intelligent Systems and Computing. 1ed. Cham: Springer, 2018;602:153-62.

[13] Ramos E, Reis DC, Tirloni AS, Moro ARP. Thermographic analysis of the hands of poultry slaughterhouse workers exposed to artificially cold environment. Procedia Manufacturing. 2015;3:4252-9.

[14] Tirloni AS, Reis DC, Dias NF, Moro ARP. Evaluation of Worker Satisfaction with the Use of Hand Tools in a Poultry Slaughterhouse. In: Goonetilleke RS, Karwowski W, editors. Advances in Physical Ergonomics \& Human Factors. Cham: Springer, 2019;789:476-88.

[15] Colombini D, Occhipinti E. Risk Analysis and Management of Repetitive Actions: A Guide for Applying the OCRA System (Occupational Repetitive Actions), 3rd ed. CRC Press, Boca Raton. 2017.

[16] International Organization for Standardization. Ergonomics - Manual Handling - part 3: Handling of low loads at high frequency. ISO 11228-3:2007. Geneva: ISO, 2007. 
[17] Tucker P. The impact of rest breaks upon accident risk, fatigue and performance: a review. Work \& Stress. 2003;17(2):123-37.

[18] Faucett J, Meyers J, Miles J, Janowitz I, Fathallah F. Rest break interventions in stoop labor tasks. Applied Ergonomics. 2007;38(2):219-26.

[19] Ross HA, Russell PN, Helton WS. Effects of breaks and goal switches on the vigilance decrement. Experimental Brain Research. 2014;232(6):1729-37.

[20] Arlinghaus A, Lombardi DA, Courtney TK, Christiani DC, Folkard S, Perry MJ. The Effect of Rest Breaks on Time to Injury - a Study on Work-related Ladder-fall Injuries in the United States. Scandinavian Journal of Work, Environment \& Health. 2012;38(60):560-7.

[21] Lombardi DA, Jin K, Courtney TK, Arlinghaus A, Folkard $\mathrm{S}$, Liang Y, et al. The effects of rest breaks, work shift start time, and sleep on the onset of severe injury among workers in the People's Republic of China. Scandinavian Journal of Work, Environment \& Health. 2014;40(2):146-55.

[22] Fischer D, Lombardi DA, Folkard S, Willetts J, Christiani DC. Updating the "Risk Index": A systematic review and meta-analysis of occupational injuries and work schedule characteristics. Chronobiology International. 2017;34(10):1423-38.

[23] Tirloni AS, Reis DC, Ramos E, Moro ARP. Association of bodily discomfort with occupational risk factors in poultry slaughterhouse workers. Dyna. 2017;84(202):49-54.

[24] Reis DC, Reis PF, Moro ARP. Assessment of risk factors of musculoskeletal disorders in poultry slaughterhouse. In: Azeres P, Baptista JS, Barroso MP, et al. editors. Proceedings book of the international symposium on occupational safety and hygiene - SHO2015. 1st ed. Guimarães-Portugal: SPOSHO v.1, p.294-296, 2015. ISBN 978-989-98203-3-3.

[25] Camargo VM. A implementação de pausas psicofisiológicas em uma indústria de processamento de frango: a perspectiva dos trabalhadores. Florianópolis: UFSC, 2015. 136p. [Dissertação de Mestrado].

[26] Tirloni AS, Reis DC, Santos JB, Reis PF, Barbosa A, Moro ARP. Body discomfort in poultry slaughterhouse workers. Work. 2012;41(Suppl.1):2420-5.
[27] Brasil. Norma Regulamentadora No 17 - Ergonomia, Portaria $\mathrm{GMN}^{\circ}$ 3.214, 08 de junho de 1978. Brasília: Ministério do Trabalho, 1978.

[28] Chakrabarty S, Sarkar K, Dev S, Das T, Mitra K, Sahu S, et al. Impact of rest breaks on musculoskeletal discomfort of Chikan embroiderers of West Bengal, India: a follow up field study. Journal of Occupational Health. 2016;58(4):365-72.

[29] Januario LB, Madeleine P, Cid MM, et al. Can exposure variation be promoted in the shoulder girdle muscles by modifying work pace and inserting pauses during simulated assembly work? Applied Ergonomics. 2018;66:151-60.

[30] Dababneh AJ, Swanson N, Shell RL. "Impact of added rest breaks on the productivity and well being of workers". Ergonomics. 2001;44(2):164-74.

[31] Ramsey JG, Musolin K, Mueller C. Health hazard evaluation report: evaluation of carpal tunnel syndrome and other musculoskeletal disorders among employees at a poultry processing plant. Cincinnati, OH: U.S. Department of Health and Human Services, Public Health Service, Centers for Disease Control and Prevention, National Institute for Occupational Safety and Health, HHE 2014-0040-3232, 2015 [cited 2020 May 18]. Available from: https://www.cdc.gov/niosh/hhe/reports/pdfs/20140040-3232.pdf.

[32] Harmse JL, Engelbrecht JC, Bekker JL. The Impact of Physical and Ergonomic Hazards on Poultry Abattoir Processing Workers: A Review. Int J Environ Res Public Health. 2016;13(2):197.

[33] Tirloni AS, Reis DC, Borgatto AF, Moro ARP. Association between perception of bodily discomfort and individual and work organisational factors in Brazilian slaughterhouse workers: a cross-sectional study. BMJ Open. 2019;9(2):e022824.

[34] Folkard S, Lombardi DA, Tucker PT. Shiftwork: safety, sleepiness and sleep. Industrial Health. 2005;43(1):20-3. 